\title{
"She's More Like a Guy": The Legacy of Gender Inequity Passed on to Undergraduate Engineering Students
}

\section{Dr. Jeanne Christman, Rochester Institute of Technology (CET)}

Dr. Jeanne Christman is an Associate Professor and Associate Department Chair in the Department of Electrical, Computer and Telecommunications Engineering Technology. She holds a BS in Electrical Engineering, an MS in Computer Science and a PhD in Curriculum, Instruction and the Science of Learning. Utilizing her educational background, her teaching specialty is digital and embedded system design and her research areas include engineering education culture, equity in engineering education and increasing diversity in STEM through transformation of traditional teaching methods.

\section{Dr. Randy Yerrick, Fresno State University}

Randy Yerrick is Dean of the Kremen School for Education and Human Development at Fresno State University. He has also served as Professor of Science Education at SUNY Buffalo where he Associate Dean and Science Education Professor for the Graduate School of Education. Dr. Yerrick maintains an active research agenda focusing on two central questions: 1) How do scientific norms of discourse get enacted in classrooms and 2) To what extend can historical barriers to STEM learning be traversed for underrepresented students through expert teaching practices? For his efforts in examining science for the under-served, Dr. Yerrick has received numerous research and teaching awards including the Journal of Research in Science Teaching Outstanding Research Paper Award, Journal of Engineering Education "Wickenden Best Paper Award" (Honorable Mention), the Most Outstanding College Science Teacher Award from the Science Teacher Association of New York State, the Teaching Innovation Award from The State University of New York, and The STAR Award for Outstanding Mentoring. He has held fellowships in several organizations such as the National Partnership for Advanced Computational Infrastructure, the San Diego State Center for Teaching and Learning, and has on the Board of Directors for the National Association for Research in Science Teaching, served as their Director of Communications, and served for nearly 20 years as an Apple Distinguished Educator. Professor Yerrick is also a founding Member of the Science Educators for Equity, Diversity and Social Justice. 


\section{"She's more like a guy": The Legacy of Gender Inequity Passed on to Undergraduate Engineering Students}

\section{Background}

Gender homogeneity in engineering education has been a concern for over five decades, as the percentage of undergraduate engineering degrees awarded to women has remained lower than $20 \%$ [1], [2]. Female underrepresentation is even greater for practicing engineers, where women hold less than $15 \%$ of all engineering positions in the U.S. In some sub-disciplines (e.g., electrical and computer) women represent less than $10 \%$ of the workforce [3]. Despite more than 30 years of research documenting the underrepresentation of women in engineering fields, reversing the trend has been a challenge [4], [5].

A number of explanations have been proposed for this phenomenon. Explanations often characterize underrepresented engineering students leaving the discipline as deficient, unprepared, or otherwise unfit for the profession. Blickenstaff's [6] meta-analysis demonstrated that bias persists, despite evidence challenging engineers' explanations for the exodus. He explored common explanations, such as the lack of role models, along with other long-standing explanations like biological differences, lack of academic preparation, attitude, curricular and pedagogical approaches, unreceptive academic climate, cultural pressures, and engineering epistemological stances. Although many factors contribute to gender underrepresentation, the majority of depictions in engineering education literature position engineering faculty outside the locus of control and situate the problem upon students and (perceived) deficit characteristics.

As authors, we critically analyzed the context for engineering attrition. We set aside the convenient belief that the ultimate responsibility of reform lies in poor preparation of girls in K-12 education. As a result of three decades of initiatives, girls have made consistent gains to close the gap in K-12 mathematics and science achievement [7]. Girls are now graduating from high school having taken equal numbers of mathematics and science credits and earning higher grades in those subjects than their male classmates. Additionally, girls have shown comparable success in Advanced Placement courses, have as strong of a grade point average, and are equally likely to select a STEM field of study in undergraduate education [8]-[10]. Despite such gains in K-12 education, enrollment is still more than $80 \%$ male by the third year in most university engineering programs. Aware of these statistics, we chose to not interrogate students, but the higher education learning environment itself, which many have described as "chilly" toward women [11], [12]. We questioned such assertions that increasing recruitment efforts and hiring more women as role models will affect the retention rates for women, if the environment is not addressed. Our assumptions are based upon research like Brainard and Carlin [13] who reported 20\% of women students perceived no barriers in engineering upon entering college, but only $3 \%$ of those women felt the same way after three years of engineering coursework.

The problem with examinations of gender gaps in engineering education that focus exclusively on women students, is that they fail to attend to existing educational practices. Equity researchers Beddoes and Borrego [14] analyzed 88 engineering educational research articles and found a limited use of alterative frameworks, specifically various forms of feminist theory. They argued 
many branches of feminist theory are underutilized within existing scholarship for explaining the norms and practices in the culture of engineering education; the impermeability of traditional teaching practices; and even the interests and persistence of female engineers.

Feminist theories offer alternative approaches through which we can interpret gendered interactions situated within cultural contexts, especially those that affect the well-being of one member of a cultural group at the cost of another [15]. Harding [16] posited that men and women experience the world differently, and their gendered motivations, experiences, knowledge, and agendas affect the way others respond to them. Stereotypically, males thrive in competitive environments, striving to work alone in a style of rugged individualism and survival while many women prefer collaborative and supportive environments [17]. Such a cultural critique could explain why women seek more collaborative academic and professional settings and how competitive environments can elicit anxiety, leading to attrition [18]. Feminist theories are also more apt to recognize knowledge as socially situated. This can explain why underrepresented students in engineering often have little influence regarding what counts or what is considered "exchange value" within their community. As a result, inequity is sustained through the cultural beliefs and practices of the majority, and the ability for others like them to practice, emulate, or be socialized into these norms, rituals, and positions of power [19].

We are not suggesting a rigid, or polar standard of gender norms and values in engineering, however. Various researchers argue that gender construction is not a binary phenomenon [20] and simply inserting one gender in the place of another would not result in a transformation of engineering culture [21]. As a socially constructed identity, gender should not be treated as a predetermined, innate state - fixed by nature and unaffected by sociocultural norms. Research suggests, "the great majority of us combine masculine and feminine characteristics, in varying blends, rather than being all one or all the other" [22]. The enactment of gender within educational environments is particularly salient to research on women's experiences in the male-dominated culture of engineering education. Many women, including the first author, have demonstrated success within the traditional engineering culture. Likewise, many men have not found success, despite their gender-afforded privilege. The process of becoming an engineer involves the formation of an engineering identity, which includes adapting to the norms and behaviors of the discipline [23]-[25]. Though many women can, and do, form a positive engineering identity, some have succumbed to domestication as they have been "required to conform uncritically to established norms in a community of practice, and are prevented from using their own craft and/or professional knowledge to assist the community to grow" [26]. Women engineers often negotiate their contexts by accepting typical male norms in order to persist or to assure their own success [27]. Unfortunately, research has demonstrated that women in these roles may also perpetuate bias by reproducing patterns of inequity through teaching methodologies and discourse interactions [28]. Consequently, women engineering professors may unknowingly sustain an unwelcoming culture toward females in their classrooms.

As engineering faculty and researchers, we find an alternative critique appealing and a useful stance through which to view members' interactions and instantiated beliefs. We were curious if engineering educators recognized and were aware of gendered beliefs and practices within the engineering culture. It is our belief that only when the entire discipline engages in an honest critique, can a new culture within engineering, one which does not enforce a monolithic view of 
success across the profession, be established. In undertaking this research, we sought explanations from engineering insiders to understand how they perceive gendered interactions, which heavily influence the development and socialization of engineers. To this end, we ask the following research question: To what extent are gendered ways of thinking, speaking, and acting passed on within instructor-student interactions?

\section{Methodology}

Ours is a qualitative examination of undergraduate engineering culture. As two STEM education researchers, one White, female engineering educator and one White male science educator, we employed ethnographic methods in our qualitative case study to better understand faculty and student interpretations of classroom behaviors, traditions, and beliefs. Both Creswell [29] and Spradley [30] favor ethnographic methods in exploring cultural knowledge and practices. As in most studies leaning upon ethnographic traditions, researchers were an integral component of the research process [31]. We acknowledge that as instruments of the analysis, our subjectivities [32] and our experiences all influenced the path of this investigation. As such, our personal knowledge and interests were addressed to prevent our own subjectivity from standing in the way of "truth", or resulting in findings that that were nothing more than what we were specifically looking for [33]. Addressing our subjectivity allowed us to consciously identify and focus on our preconceived opinions and perspectives that influenced what we chose to look for and how we interpreted what we saw [32].

Data for this research were collected in the colleges of engineering at three large universities in the Northeastern United States. Two of the universities have Carnegie classification of R1 and one has R2. Participants included engineering professors and undergraduate engineering students from all three sites. Eight male and four female professors from various departments within the colleges of engineering were chosen for interviews and class observations. Care was taken to purposefully recruit professors with varying years of teaching experience and distinct rankings of associate and full professor. To increase the transferability of our findings to the wider collection of engineering programs, we chose professors that represented a variety of engineering sub-disciplines. Each professor interview followed a semi-structured interview protocol [31] and lasted approximately 1 hour. In most cases, the interviews were conducted before a class observation. This sequence was chosen due to the common discrepancy between what educators say during interviews and what they do in their classrooms.

Twenty students, eight men and 12 women, participated in this study. As with the professors, purposeful sampling was employed to ensure the inclusion of a variety of perspectives. For depth of data, we included students from all three universities, representing all four year levels and a variety of sub-disciplines. The interviews with students were conducted in six single-gender focus groups, four of women and two of men. Focus group interviews with men and women students also followed a semi-structured interview protocol [31] and lasted one and one half hours.

We built trustworthiness into the research account several ways. Data were collected from five different sources (female professors, male professors, female students, male students and classroom observations) for triangulation, to enhance meaning and provide thick description. As an additional measure of member trustworthiness, we performed member checking by re- 
presenting actual data coupled with our interpretations to the participants of our study. If there were corrections needed in our account, the participants were allowed to change, elaborate or supplement their accounts with additional data for clarification. In the case of professors, member checking also included debriefing interviews, which followed immediately after the observation of their class. In those meetings, we asked specific questions on how the teaching that we witnessed supported the descriptions of their teaching given in the initial interview.

While transcribing the interviews and classroom observations, analytic and reflective notes [34] were generated and logged in an audit trail, while the identification of codes and their origins were carefully noted. It was also during this process that emerging themes were identified, which informed interview protocols for member check interviews. Throughout the coding process, we compiled transcripts and field notes with the help of hyperRESEARCH. We assigned codes to each data set, extracted the list of codes and used those to assign codes to the next data set, adding new codes as they were generated.

Once all qualitative data were completely coded, we analyzed them to identify themes in the codes. With trustworthiness in mind, we identified themes that were common to at least three different data sets and put aside others which were not. Again using hyperRESEARCH, we grouped all of the data we wished to include in the findings by themes. We identified each piece of evidence by its source, assigning pseudonyms in the process. Themes which were retained were well supported, revealing the most credible and significant data.

\section{Findings}

In Christman, Yerrick \& Valentine [35], we found there were no appreciable differences in the expressed beliefs and teaching methods of the female engineering educators we encountered from those of their male colleagues. They conducted their classrooms in similar manners and revealed the same ideals regarding what it takes to achieve success in undergraduate engineering. Like the male faculty participants, the women could not provide explanations for the underrepresentation of women beyond student deficits, lack of role models and societal influences. Additionally, none of the female faculty members proposed any new ideas for improving retention of female students nor did they identify any pedagogical shifts that could be employed to make engineering education more welcoming for women.

We were curious as to whether the same congruence we saw among male and female faculty members would be found among male and female undergraduates. We wanted to explore whether the homogenous beliefs common to faculty members were learned, enacted, and passed on to future male and female engineers alike. Unlike the faculty, we did find differences between the male and female engineering students' responses. Men echoed the beliefs of their professors without any apparent awareness of the male-normed culture into which they had been encultured, while the women expressed awareness of implicit and explicit bias and gendered ways of socializing neophyte engineers.

In every interview and focus group, we asked participants why they believed women are underrepresented in engineering. Similar to their professors, the male engineering students blamed society and parents and attributed part of the problem to gendered upbringings. 
Kevin: I am pretty sure it is just our culture. In terms of the things children are pushed towards. Brendan: It's kind of a self-sustaining thing. When we are children girls are pushed towards dolls and pink, whereas guys have Legos and the Tetrix and all the more technical things that they keep expounding until guys have a more innate interests in those types of things. That is why STEM is more predominantly male and continues to be.

Brody: We love building things. That may stem from the way you were raised. I built things with my dad and that is how I became mechanically inclined. Girls, that is not typically what they do.

Chaz: You look at the toys that kids get. A boy will get Legos and toolbox girls get a dollhouse or one of those Easy Bake ovens.

In addition to perceived gendered upbringings, the men students pointed to inherent biological differences in ability as a barrier to success for women in engineer. This belief stood in contrast to that of the faculty participants. None of the professors even alluded to a gender difference in aptitude. Some even praised women students for their academic strengths. The male engineering students, however, pointed to a difference in mathematics ability as a reason why girls do not choose engineering. The conversation below followed a discussion regarding how the mathematics requirements for engineering students added to the difficulty of the discipline. For the male students, it obviously followed that weaker mathematics skills would drive women students away.

Todd: I just think it's that girls and guys think differently

Brody: Oh it's psychologically proven that we do. Men have a stronger left side of the brain Todd: I think they are less drawn to the sit down and do math all day. My sister is really, really struggling with Algebra 1, like pre-Algebra. That's weird because I could do it at that age. She is like "I don't get it".

Brody: My parents are very, very math orientated. My mom's an actuary and my dad's a statistician analyst so we all got the math genes. My sister got the math gene but she still struggled. Math is definitely genetic we found out but she just didn't have the same drive to do the math, she's more communications based. It's just kind of how it works out.

Their line of reasoning would have been expected 30 years ago when girls consistently scored lower than boys on standardized mathematics tests, but these men started high school around 2010, after girls had leveled the mathematics ability playing field [7], [36]. Yet despite the evidence around them, the men students fell back on an outdated argument and then used stories of their own sisters to justify it. They believed there was an ability difference, especially in mathematics that kept women from being successful in engineering. If these students were unabashed in telling it to a woman professor and researcher, we were left questioning how this misinformed belief manifested itself in their treatment of their female classmates.

It was not long before we received a troubling answer to our question, as we overheard several male students talking amongst themselves before the start of an observed class. Much to the dismay of this group of students, the professor had not allowed them to self-select project groups and instead used group formation software to create heterogeneous groups. As their conversation progressed, it became apparent that several of these male students had not previously been in a group with a female classmate, and were not happy that they had to be now. In reference to the 
girls in their class, they callously used names such as "annoying girl", "space cadet" and "coffee bitch". Their annoyance with the assigned groups was obvious except for one student whom the others dubbed "lucky"; he was in a group with Nicki. Their conversation continued as follows:

"Lucky" student: But he made it so most of the groups have a girl in them

Student 1: Yeah but you have Nicki - she's like a guy

Student 2: Nicki is like a bro. She doesn't count as a girl

Student 3: She's kinda masculine for a girl, she doesn't even wear dresses for presentations

Not only was this exchange harmful and inappropriate, it demonstrated how deeply ingrained the idea was that in order to be a "good" engineer, it is necessary for a woman to look and act like her male counterparts. Unknowingly, this group of students was perpetuating discrimination against individuals who have the potential to be successful in the field.

In contrast to their male classmates, female students did not blame parents, society or the lack of mathematics skills for the low number of women in engineering. They instead pointed to a general misunderstanding of the type of work done by engineers. As we only interviewed women who had chosen to study engineering, these female student participants provided valuable insight on the major choices of their high school classmates. They shared stories of friends who were the top mathematics student in the school or had received fives on AP Physics and Chemistry exams. Their friends were strong students who clearly had the aptitude for engineering, but had chosen different fields. We asked each of the female focus groups why their highly qualified friends had not chosen to study engineering. Most of the women explained it was because their friends believed engineering careers were anti-social and not about working with, or helping people.

Sophie: I know a lot of my friends who are very social thought that engineering was anti-social. They said they wanted to work with kids, they wanted to be a pediatrician, they wanted to talk to people. They wanted that interaction and they were afraid that in engineering they would be in a cubicle by themselves, not talking to anybody.

Jane: I know a lot of my friends that went to State U were good at math and science and a lot went to more medical fields. Some of them just did neuroscience and that kind of science, but they all wanted fields where they could work with people.

Olivia: Well when people think engineering they don't think lively and friendly, they think dirty and busy. I don't think engineering is understood as well.

As was discussed by a few of the engineering professors, the lack of understanding of engineering as a social and/or helping field has been documented. As such, we questioned our participants as to whether they viewed it differently. Most revealed they were aware of the ways in which engineers helped society and worked with people. However, some of the women students indicated that the social and helping nature of the discipline was not evident in the classes they had taken. They expressed concern that the ways in which engineering is taught does nothing to change the view of engineering held by their high school friends. When we probed further regarding these concerns, they explained that the primary mode of instruction was through didactic lectures that only stopped for the instructor to ask questions of the class. For the women students, a lecture format with an emphasis on formulas and facts did not connect to the actual work 
engineers perform in the field, and did not provide an opportunity for them to work together and discuss their ideas.

The women engineering students reinforced the importance they placed on being able to express and argue their opinions when they described what they liked about some of their general education classes. Yuna sheepishly admitted that Sociology had been one of her favorite classes thus far, and her favoritism was based on its format as a roundtable discussion.

Yuna: It was a smaller class size, it wasn't in a big lecture hall, and we had really, really good discussions in there. We sat around a table and discussed the readings and argued things. It wasn't the bad kind of arguing, but the kind where somebody questions what you said and forces you to look at it differently. Not everybody liked it because you had to participate. That may be why other students tell you they don't like Liberal Arts classes. My guy friends hate them.

Susan smiled as she listened to Yuna and dovetailed with her similar fondness for class discussions.

Susan: I like Liberal Arts classes too because they allow for more fluid discussions and exchanges of ideas. In math, science and engineering classes, people believe that there is only one right method and one right answer for every problem, but people in Liberal Arts classes tend to be more open to alternative approaches and the opinions of others.

The free flow of ideas and the exploration of alternative approaches that these women students favored was missing from the engineering classes we observed for this study. Knowing that in the culture of engineering education many insiders do not value Liberal Arts classes, the women students were almost embarrassed to admit they liked them. Engineering education, with its deep positivistic roots and search for objectivity, had made these women question the value of a learning environment they clearly enjoyed. Not only did that get that message implicitly in their engineering classes, we were told of a first-year engineering instructor who, "Put down Liberal Arts classes, calling them useless, every chance he could get."

Beyond the lack of classroom discussion, the women shared with us that the examples chosen by their professors were not relevant to the work done by most engineers and especially not the work that interested them. Although they were persisting in engineering, they articulated frustration at the uselessness of some of the problems they were being asked to solve.

Emma: The problems are not about things we care about and don't even make sense. We get problems like, "Oh this man drove his car into a lake. Figure out the pressure to break the car window." or random things that could be applied theoretically in the real world, but nobody drowning in a car is really going to calculate the pressure. They are just going to do the logical thing and break the window so there is no pressure differential.

Other women described their professors' use of examples from traditional male domains that resulted in them feelings left out. 
Yuna: I think this school is awesome with their professors. They encourage you and all but I do think that some of them create classroom environments that are more boy-friendly. Where it's like this is just a class where the boys can kick back, and I'm going to use examples that relate code to the engine of a car. You know what I am talking about?

Asia: I do.

Yuna: And then obviously in that kind of environment if you raise your hand and raise a question like, "Hey what is the whatever of a car? What does that do? I don't understand the analogy." You probably will get laughed at.

Asia: Yeah, I definitely had that experience. Sometimes teachers just use examples and stuff that are more geared towards guys, and I'm just like, "I don't relate to this at all," and it just makes me enter the classroom being like, "This isn't for me. Why do I want to be here? What's the point? You're just going to write me off."

In order to build a credible account, we conducted follow-up observations to see for ourselves what these female students were describing regarding the way engineering was taught. We used their interview responses to help inform our classroom observations, noting that the women students indicated a lack of social interactions and lamented the absence of opportunities for classroom discussions. Additionally, we sought to confirm or refute their descriptions of classrooms that presented engineering concepts in traditionally masculine domains.

Upon entering one classroom, we took note of the physical location the women students had selected. The only four women in the class had arranged themselves such that they could see the front of the room but also converse with each other. As the lecture began, a serious tone sent a hush across the whole class. Female students' verbal interactions, coupled with actions such as entering numbers in a calculator and pointing to each other's notes, indicated that they were actively helping one another to understand the fine points of their instructor's presentation. With her back to the classroom, the instructor continued to write her notes on the whiteboard, pausing periodically to pose a question. Unlike her male colleagues, who we witnessed asking questions to the class in general, she asked students to volunteer their answers. The professor called on a female student with her hand raised to answer a question, but before she could finish, a male student sitting in the first row called out his answer. Throughout the lecture, the male student continued to make comments and to answer many of the questions that the instructor asked. As students were filing out after class, one of the female students approached him and, with an agitated voice, asked, "Would you please raise your hand when you have something to say?"

In our follow-up interview with the professor, we asked how she felt about the behavior of the male student. Her response was simply, "I'm just happy somebody is paying attention. Bobby is the type that wants to impress me with what he knows." Pressing further, we asked specifically why she had allowed him to talk over other students who had raised their hands. It was evident in her response that she lacked awareness of the frustration her female students experienced as they were denied the opportunity to contribute their answers and ideas to the discourse in the classroom. Shrugging her shoulders, she replied, "oh the girls have him in several classes and they are used to him by now." We were amazed that what we saw in 50 minutes from the back of the room went without notice from the front. 
Unfortunately, the incident described above was not isolated. The silencing of students with hands raised appeared to go unnoticed by the professors we observed; as none attempted to put an end to the students calling out answers. However, the women students we spoke to were all well aware of it. Among the women, there were varying levels of acceptance of this common classroom dynamic. Some, who were early in their education, were still angry that it went on. For example, Yuna, a second-year student, told us, "I resent the student who shouts out, and the professor for acknowledging them because it discourages people like me who patiently and respectfully raise their hand." In contrast, some women students, especially those in upper level classes, were willing to follow the unwritten rule of calling out answers. Whether they were told explicitly or figured it out after several years in the engineering classroom, they knew in order to have their voice heard, they had to shout out answers. Susan told us, "It's a great feeling when you can express your opinion or be first to the correct answer. If the teacher isn't going to call on you, you just have to announce it." Silencing others in order to be heard was a masculine behavior and part of the culture of engineering education that women were aware of, felt marginalized by, yet began to adopt in order to obtain recognition for their engineering knowledge. Having accepted this behavior as part of what it takes to be an engineer many years prior, women professors allowed it to continue in their own classroom without consideration for how it affected their female students.

\section{Discussion and Implications}

In these findings, we have provided examples of how enculturation into the biased norms of engineering culture is evidenced in persisting students. Consistent with the views expressed by both male and female professors, male engineering students were quick to attribute the underrepresentation of women to forces outside the control of the engineering discipline. Male students focused their attention even more finely on the presumed gender differences in mathematics ability. It is not clear whether male members carried this bias with them from their pre-college education or whether they adopted these beliefs from their professors. However, this assertion was one of several manifestations of the belief, held by many faculty members as well, that not all students are cut out to be engineers [37]

It is important to point out here that the female engineering students did not support the multiple explanations put forth by the engineering professors and the male students. They did not blame parents, gendered toys, lack of female faculty, or K-12 teachers. While the women students did not specifically point to any explicit facets of the engineering culture as the reason for women's underrepresentation, they clearly described how some long-standing beliefs and pedagogical approaches within the discipline left them feeling disconnected from it. As women persisting in the major, they each demonstrated some degree of domestication [26] and, as such, saw the culture as what they had to endure if they wanted to become an engineer. As Judy recounted, "If you want it bad enough you will just suck it up and do it." She had already bought into the well-documented belief system permeating engineering education [38]. Although there was some evidence of unease with the norms they were adapting to, these women had accepted them as the only path to success in engineering.

Finding similar beliefs among male and female professors and among male students and faculty was not entirely surprising given the well-documented reproductive processes in engineering education. Engineering professors promote and nurture students with attributes and attitudes like 
their own. The classroom example we provided is just one of several where we observed a female instructor teaching or managing the classroom in ways that the female students told us they did not feel included. This provided evidence that, despite their discomfort in doing so, women persist more often in the engineering selection process if they conform uncritically to the norms of the discipline [27]. Consequently, we observed a rather homogenous set of beliefs across instructors, regardless of gender.

Though we do not want to suggest our findings are generalizable nor a representative sample of all engineering professors, our findings leave us skeptical that an approach of hiring more female engineers without change to the discipline will have any substantive impact in increasing the success and retention of female engineering students. The female professors we interviewed reflected findings from prior studies [39], [40]. They believed that their ability to succeed came without support, help, or assistance, and they approach mentorship from the perspective that those who come after them should be able to do the same. Like generations of engineers before them, they unknowingly continue the legacy of gender inequity with their students. Somewhere along their journey to the front of the classroom, they had forgotten what it was like to be sitting in that classroom. As argued by Turner [28], marginalized faculty 'socialized for success,' may reproduce patterns of inequity.

We believe that engineers are fair minded and rational and do believe that, when research demonstrates a clear connection between gendered teaching practices and a consequential exodus from the field, engineers will take heed. We therefore call upon researchers to explore more critically learning contexts with an eye toward exposing the implicit White, male dominant norms and their effects on the discipline. As many have shown [12], [41] engineers have been rather uncritical of their working contexts - looking for alternate explanations and anemic solutions like recruitment to resolve inequity. Research on the beliefs that engineering educators hold toward equity; on transformative and inclusive teaching practices; and on efforts to foster other competing values in engineering can also paint a new vision as to whether different models of success and support can thrive.

What is required is that engineering instructors see their actions, their teaching, their mentoring, and their powered positions as intricately tied to the success of women in engineering. It may not be a single change in practice or in assessment or in socialization, but as Sonnert [42] argued, an entire collection of various events and characteristics of culture, which contribute to the exodus of women from engineering majors. For this reason, we believe it is important to promote a selfreflexivity about the engineering culture - one which interrogates any and all prior beliefs about "leaky pipelines" against actual data, and one which seeks honest and critical evaluation of what many young female engineers, as in our study, have recognized and that other studies are demonstrating. There are implicit barriers to a woman's success in engineering. We agree with Jawitz and Case [43] who argued a new culture needs to be established within the ranks of engineering education. Rather than seeking old and unfruitful ways of thinking like recruitment and role models, engineers need to find ways to explicate and work against a hostile culture for females. We side with Bastalich, et al [11] who argued, "The problem is not that engineering cannot attract women engineers, or that femininity makes women unsuited to engineering work. The problem with engineering is that the workplace culture polices a narrow set of masculine 
norms and is intolerant of diversity. Within the engineering workplace culture 'women', or anyone who fails to conform to strict codes of masculine conduct, is cast as an 'outsider' or 'foreign'."

Until the culture shifts, moneys spent on recruitment and role models will likely continue to have the same weak effect they have had, which has changed some fields of engineering like computer and electrical engineering only $4 \%$ in four decades. It is time to live up to the creed that a more diverse engineering field is a more agile, more effective, and stronger field. Engineering education should be about acquiring the skills needed to solve society's challenges and not about conforming to a long-standing and outdated identity.

\section{References}

[1] (2013). NSF 13-327, Science and Engineering Degrees: 1966-2010. [Online] Available: http://www.nsf.gov/statistics/nsf13327/content.cfm?pub_id=4266\&id=2

[2] (2019). NSF 19-304, Women, minorities and persons with disabilities in science and engineering. [Online] Available: https://ncses.nsf.gov/pubs/nsf19304/data

[3] (2017). NSF 17-310, Women, Minorities, and Persons with Disabilities in Science and Engineering. [Online] Available: https://www.nsf.gov/statistics/2017/nsf17310/data.cfm

[4] L. L. Long and J. A. Mejia, "Conversations about diversity: Institutional barriers for underrepresented engineering students," Journal of Engineering Education, vol. 105, no. 2, pp. 211-218, 2016.

[5] D. Riley, "Engineering and Social Justice," Synthesis Lectures on Engineers, Technology, and Society, vol. 3, no. 1, pp. 1-152, 2008.

[6] J. C. Blickenstaff, "Women and science careers: Leaky pipeline or gender filter?," Gender \& Education, Article vol. 17, no. 4, pp. 369-386, 2005.

[7] T. Scafidi and K. Bui, "Gender similarities in math performance from middle school through high school," Journal of Instructional Psychology, vol. 37, no. 3, pp. 252-255, 2010.

[8] D. Baker, "Equity issues in science education," in International handbook of science education, B. J. Fraser and K. G. Tobin Eds. Boston, MA: Kluwer, 1998, pp. 869-896.

[9] D. Baker, "Where is gender and equity in science education?," Journal of Research in Science Education, vol. 39, no. 8, pp. 659-663, 2002.

[10] J. B. Kahle, "Will girls be left behind? Gender differences and accountability," Journal of Research in Science Teaching, vol. 41, no. 10, pp. 961-969, 2004.

[11] W. Bastalich, S. Franzway, J. Gill, J. Mills, and R. Sharp, "Disrupting masculinities: Women engineers and engineering workplace culture," Australian Feminist Studies, vol. 22, no. 54, pp. 385-400, 2007.

[12] D. Rice. The STEM pipeline: Recruiting and retaining African American female engineers [Online] Available: https://digitalcommons.uncfsu.edu/jri/vol2/iss 1/5

[13] S. G. Brainard and L. Carlin, "A six-year longitudinal study of undergraduate women in engineering and science," Journal of Engineering Education, vol. 87, no. 4, pp. 369-375, 1998.

[14] K. Beddoes and M. Borrego, "Feminist theory in three engineering education journals: 1995-2008," Journal of Engineering Education, vol. 100, no. 2, pp. 281-303, 2011.

[15] M. Lloyd, Judith Butler: From norms to politics. Malden, MA: Polity, 2007. 
[16] S. Harding, "Feminist standpoint epistemology," in The gender and science reader, M. Lederman and I. Bartsch Eds. New York: Routledge, 2001, pp. 145-154.

[17] B. Brand and M. Kasarda, "The influence of social interactions on female students retention in two engineering programs," Insights on Learning Disabilities, vol. 11, no. 1, pp. 33-45, 2014.

[18] M. Niederle and L. Vesterlund, "Gender and competition," Annual Review of Economics, vol. 3, no. 1, pp. 601-630, 2011.

[19] N. Riley, "Challenging demography: Contributions from feminist theory," Sociological Forum, vol. 14, no. 3, pp. 369-397, 1999.

[20] C. L. Ridgeway and S. J. Correll, "Unpacking the gender system," Gender \& Society, vol. 18, pp. 510-531, 2004.

[21] S. Harding, The feminist standpoint theory reader. New York, NY: Routledge, 2004.

[22] R. Connell, Second, Ed. Gender in world perspectiv. Malden, MA: Polity Press, 2009.

[23] K. L. Tonso, "Engineering identity," in Cambridge handbook of engineering education research, A. Johri and B. M. Olds Eds. New York, NY: Cambridge University Press, 2014, pp. 267-282.

[24] R. Stevens, K. O'Connor, L. Garrison, A. Jocuns, and D. M. Amos, "Becoming an engineer: Toward a three dimensional view of engineering learning," Journal of Engineering Education, vol. 97, no. 3, pp. 355-368, 2008.

[25] K. L. Tonso, "Student engineers and engineer identity: Campus engineer identities as figured world," Cultural Studies of Science Education, vol. 1, no. 2, pp. 273-307, 2006.

[26] A. J. Rodríguez, "The politics of domestication and curriculum as pasture in the United States," Teaching and Teacher Education, vol. 22, pp. 804-811, 2006.

[27] H. Dryburgh, "Work hard, play hard: Women and professionalization in engineeringadapting to the culture," Gender and Society, vol. 13, no. 5, pp. 664-682, 1999.

[28] C. S. Turner, "Lessons from the field: Cultivating nurturing environments in higher education," Review of Higher Education, vol. 38, no. 3, pp. 333-358, 2015.

[29] J. W. Creswell, Qualitative inquiry and research design: Choosing among five traditions. Thousand Oaks, CA: Sage Publications, 1998.

[30] J. P. Spradley, Participant Observation. New York: Holt, Rinehart and Winston, Inc, 1980.

[31] E. G. Mishler, Research interviewing: Context and narrative. Cambridge, MA: Harvard University Press, 1986.

[32] A. Peshkin, "In Search of Subjectivity - One's own," Educational Researcher, vol. 17, no. 7, pp. 17-21, 1988.

[33] M. Drapeau, "Subjectivity in research: Why not? But...." the Qualitative Report, vol. 7, no. 3, pp. 1-15, 2002.

[34] C. Glesne, Becoming qualitative researchers: An introduction, 4th ed. Boston: Pearson, 2011.

[35] J. Christman, R. Yerrick, and M. Valentine, "Where are the women? Questioning the rationale for expanding diversity among engineering through "role models"," presented at the National Association for Research In Science Teaching Annual Conference, Baltimore, MD, 2019.

[36] J. S. Hyde, S. M. Lindberg, M. C. Linn, A. B. Ellis, and C. C. Williams, "Gender similarities characterize math performance," Science, vol. 321, no. 5888, pp. 494-495, 2008. 
[37] J. Christman, R. K. Yerrick, and M. E. Eastman. (2020). The difficult profession of engineering.

[38] R. Stevens, D. M. Amos, L. Farrison, and A. Jocuns, "Engineering as lifestyle and a meritocracy of difficulty: Two pervasive beliefs among engineering students and their possible effects," in American Society for Engineering Education Annual Conference and Exposition, Honolulu, HI, 2007.

[39] N. Ellemers, H. Van den Heuvel, D. de Gilder, A. Maass, and A. Bonvini, "The underrepresentation of women in science: Differential commitment or the queen bee syndrome?," British Journal of Social Psychology, vol. 43, no. 3, pp. 315-338, 2004.

[40] S. Mavin, "Queen bees, wannabees and afraid to bees: No more 'best enemies' for women in mangement?," British Journal of Management, vol. 19, no. 1, pp. 75-84, 2008.

[41] M. G. Eastman, M. L. Miles, and R. K. Yerrick, "Exploring the White and male culture: Investigating individual perspectives of equity and privilege in engineering education," Journal of Engineering Education, vol. 108, no. 4, pp. 459-480, 2019.

[42] G. Sonnert, "Gender equity in science: Still an elusive goal," Issues in Science and Technology, vol. 12, no. 2, pp. 53-58, 1995.

[43] J. Jawitz and J. M. Case, "Women in engineering: Beyond the stats," International Journal of Engineering Education, vol. 18, no. 4, pp. 390-391, 2002. 